\title{
A comparison of in vitro properties of resting SOD1 transgenic microglia reveals evidence of reduced neuroprotective function
}

\author{
Siranush A Sargsyann ${ }^{1 *}$, Daniel J Blackburn², Siân C Barber ${ }^{2}$, Julian Grosskreutz ${ }^{3}$, Kurt J De Vos ${ }^{4}$, Peter N Monk ${ }^{5+}$ and \\ Pamela J Shaw ${ }^{2+}$
}

\begin{abstract}
Background: Overexpression of mutant copper/zinc superoxide dismutase (SOD1) in rodents has provided useful models for studying the pathogenesis of amyotrophic lateral sclerosis (ALS). Microglia have been shown to contribute to ALS disease progression in these models, although the mechanism of this contribution remains to be elucidated. Here, we present the first evidence of the effects of overexpression of mutant (TG G93A) and wild type (TG WT) human SOD1 transgenes on a set of functional properties of microglia relevant to ALS progression, including expression of integrin $\beta-1$, spreading and migration, phagocytosis of apoptotic neuronal cell debris, and intracellular calcium changes in response to an inflammatory stimulus.

Results: TG SOD1 G93A but not TG SOD1 WT microglia had lower expression levels of the cell adhesion molecule subunit integrin $\beta$-1 than their NTG control cells [NTG (G93A) and NTG (WT), respectively, $92.8 \pm 2.8 \%$ on TG G93A, $92.0 \pm 6.6 \%$ on TG WT, $100.0 \pm 1.6 \%$ on NTG (G93A), and $100.0 \pm 2.7 \%$ on NTG (WT) cells], resulting in decreased spreading ability, with no effect on ability to migrate. Both TG G93A and TG WT microglia had reduced capacity to phagocytose apoptotic neuronal cell debris (13.0 \pm 1.3\% for TG G93A, $16.5 \pm 1.9 \%$ for TG WT, $28.6 \pm 1.8 \%$ for NTG (G93A), and $26.9 \pm 2.8 \%$ for NTG (WT) cells). Extracellular stimulation of microglia with ATP resulted in smaller increase in intracellular free calcium in TG G93A and TG WT microglia relative to NTG controls $(0.28 \pm 0.02 \mu \mathrm{M}$ for TG G93A, $0.24 \pm 0.03 \mu \mathrm{M}$ for TG WT, $0.39 \pm 0.03 \mu \mathrm{M}$ for NTG (G93A), and $0.37 \pm 0.05 \mu \mathrm{M}$ for NTG (WT) microglia).

Conclusions: These findings indicate that, under resting conditions, microglia from mutant SOD 1 transgenic mice have a reduced capacity to elicit physiological responses following tissue disturbances and that higher levels of stimulatory signals, and/or prolonged stimulation may be necessary to initiate these responses. Overall, resting mutant SOD1-overexpressing microglia may have reduced capacity to function as sensors of disturbed tissue/ cellular homeostasis in the CNS and thus have reduced neuroprotective function.
\end{abstract}

\section{Background}

Amyotrophic lateral sclerosis (ALS) is a progressive neurodegenerative disorder characterized by selective demise of upper motor neurons in the motor cortex and lower motor neurons in the brainstem and spinal cord [1,2]. Disease onset occurs in mid-life (50 to 60 years of age) and is followed by a rapid (2 to 5 years), progressive failure of the neuromuscular system and death.

\footnotetext{
* Correspondence: anna_sargsyan@hotmail.com

+ Contributed equally

'Department of Medicine, University of Colorado Denver School of Medicine, CO, USA

Full list of author information is available at the end of the article
}

Although the aetiology of ALS is yet to be fully elucidated, several factors are likely to contribute to motor neuron injury, including excitotoxic and oxidative motor neuron damage, protein aggregation, impaired axonal transport, mitochondrial dysfunction, and non-cell autonomous damage mediated through glial cells astrocytes and microglia [3,4]. Most of the current insights into disease pathogenesis come from studies on animal models overexpressing mutant forms of $\mathrm{Cu} / \mathrm{Zn}$ superoxide dismutase 1 (SOD1) [5]. Autosomal dominant inheritance of mutant SOD1 accounts for 20 percent of familial ALS (FALS) cases, or 2 percent of all ALS cases [6,7]. Overexpression of mutant forms of

\section{Biomed Central}


SOD1, including G93A, G37R and G85R mutant SOD1, in animal models faithfully replicates pathological features of the human disease [8-10]. Motor neurons expressing mutant SOD1 can escape disease if surrounded by a sufficient number of normal non-neuronal cells [11]. Conversely, normal motor neurons surrounded by mutant SOD1-containing non-neuronal cells developed signs of cellular injury with the development of ubiquitinated protein deposits [11]. Selectively reducing the levels of mutant SOD1 in motor neurons delayed early disease progression and extended lifespan by a mean of 22 percent (64 days). In contrast, reducing mutant SOD1 expression in microglia, the major immune cell of the CNS with a monocyte/macrophage phenotype, had no effect on onset and early disease but showed a large protective effect in late stage disease and ameliorated disease progression with a mean extension of survival of 99 days [12]. Moreover, a significant slowing of disease progression was observed in double transgenic G93A-SOD1/PU. $1^{-1-}$ mice when the mice received wild type but not G93A-SOD1 bone marrow transplant [13].

While the mechanisms of microglial disease propagation remain to be fully elucidated, studies indicate that mutant SOD1-overexpressing microglia may acquire an exaggerated inflammatory phenotype and neurotoxic properties following sustained activation. Low levels of inflammatory mediators are present in the cerebrospinal fluid of ALS patients [14-16] and activated microglia are detected in the CNS [17] and in the neighbourhood of degenerating motor neurons in post-mortem studies of the human disease [18]. SOD1 transgenic mouse and rat models of ALS also display signs of an inflammatory response in the CNS at all stages of the disease. Prior to the clinical signs of disease onset, microglia are in an early state of activation, and elevated levels of inflammatory mediators such as interleukin (IL)- 6 can be detected $[19,20]$. With the onset of symptoms and motor neuron cell death, fully activated (or reactive) microglia are present in the CNS and microglial production of the pro-inflammatory cytokine, tumour necrosis factor (TNF)- $\alpha$ has been demonstrated [21-24]. Elevated levels of TNF- $\alpha$, monocyte chemoattractant protein (MCP)-1, macrophage-colony stimulating factor (MCSF), interferon (IFN) $\gamma$ and transforming growth factor (TGF) $\beta[15,23,25,26]$ and an increase in cyclooxygenase (COX)-2 activity and prostaglandin (PG) E2 levels $[14,15,23,25,27]$ have been shown in mutant SOD1 transgenic mouse tissues and microglial cells. Administration of drugs such as minocycline, or inhibitors of COX-2 and peroxisome proliferator-activated receptor (PPAR), capable of reducing microglial activation, delayed both disease onset and progression in mutant SOD1 transgenic mice [28-31].
It is unknown whether microglia overexpressing the wild type form of human $S O D 1$ can acquire altered functional properties. Overexpression of wild type SOD1 in animals did not reveal any overt pathology at four months of age [32] except signs of deficiency of muscle innervation and premature aging [33-36]. Thus, wild type SOD1 could also contribute to neuronal pathogenesis. For example, autopsy material from familial as well as sporadic ALS cases revealed Lewy body-like hyaline inclusions within motor neurons that immunoreacted with anti-SOD1 antibodies [37]. Overexpression of wild type $S O D 1$ in mutant $S O D 1$ transgenic animals accelerated the disease course and shortened the lifespan of double transgenic animals [38]. Additionally, wild type SOD1 acquired toxic properties similar to those of the mutant forms of SOD1 following oxidative damage [39]. Therefore, it is possible that wild type SOD1-overexpressing microglia may also have altered cellular properties rendering the cells capable of propagating neuronal damage.

In healthy animals, microglia perform a surveillance function to maintain a physiologically healthy microenvironment [40]. They accomplish this by sampling the surrounding tissue with numerous extruding and retracting processes [41]. Alterations in the tissue microenvironment induce microglial migration to the site of damage, scavenging of extruded cellular or plasma proteins and clearance of damaged cell components through phagocytosis $[41,42]$. These dynamic effector functions of microglia are dependent on the presence of diverse surface receptors, including cytokine, chemokine, immunoglobulin, and purinergic receptors $[43,44]$. Efficient intracellular signalling, control of gene expression, and tightly regulated function of the actin cytoskeleton are also necessary for appropriate microglial effector responses [45,46]. Interestingly, in vivo recordings of labelled microglia from SOD1 G93A-overexpressing mice revealed significantly increased microglial response towards laser-induced single axon transection at preclinical age (60 days) when compared to that in control mice, and a subsequent reduction in SOD1 G93A microglial response to the same injury with disease progression (90 and 120 days) [47].

The purpose of the current study was to investigate whether overexpression of the mutant SOD1 transgene (TG G93A) or the wild type SOD1 transgene (TG WT) in microglia could significantly alter their functional properties, potentially contributing to neurodegeneration and its propagation. Due to inherent differences between the two colonies of transgenic mice that we observed in our studies, we compared the differences between NTG and TG cells within colonies, and not between colonies. Specifically, we examined non-transgenic (NTG: NTG (G93A) and NTG (WT)) and SOD1-overexpressing 
transgenic (TG G93A and TG WT) microglial surface expression of integrin $\beta-1$ (a subunit of integrin cell adhesion molecules), the ability of microglia to spread on fibronectin-coated surfaces and to migrate over astrocytic monolayers, the ability to phagocytose apoptotic neuronal cell debris, and intracellular calcium changes in response to a pro-inflammatory stimulus, extracellular ATP. Mutant SOD1 caused the most marked changes in these functions but overexpression of wild type SOD1 also produced significant changes. Thus, it is essential to examine the effects of both mutant and wild-type SOD1 when investigating the role of microglial cells in ALS.

\section{Results}

Reduced expression of integrin $\beta-1$ by TG G93A microglia Microglia were purified from mixed glial cultures of TG WT, NTG (WT), TG G93A and NTG (G93A) mice. Figure 1 presents immunostaining images of microglia in mixed glial cultures and following purification. Mixed glial cultures contained astrocytes and microglia (Figure $1 \mathrm{~A}$ and $1 \mathrm{~B}$ ) but purification using a mild trypsinisation method resulted in cultures consistent of cells positive for the monocyte/macrophage marker F4/80 - microglia (Figure 1C and 1D). To investigate if overexpression of SOD1 in microglia could alter their interaction with the extracellular matrix, cell surface expression of integrin $\beta-1$ (the $\beta 1$ subunit of integrins, a fibronectin receptor) was measured in TG G93A and TG WT microglia and compared to those in respective NTG cells. While TG WT microglia had integrin $\beta$-1 levels comparable to those in NTG (WT) cells (mean \pm standard error of the mean (SEM): $91.96 \pm 6.6 \%$ on TG WT versus $100 \pm$ $2.7 \%$ on NTG (WT) cells; Figure 1F), the expression of integrin $\beta-1$ on TG G93A microglia was modestly but significantly reduced when compared to NTG (G93A) cells (mean \pm SEM: $92.76 \pm 2.8 \%$ on TG G93A versus $100 \pm 1.6 \%$ on NTG (G93A) cells; $\mathrm{p}=0.0493$, Student's $t$ test, Figure $1 \mathrm{~F}$ ). Additional file 1 presents the data of Figure $1 \mathrm{~F}$ in more detail.

\section{Reduced spreading ability of TG G93A microglia}

To investigate whether the reduced expression levels of integrin $\beta-1$ by TG G93A microglia could impair interactions of TG G93A microglia with the extracellular matrix, the spreading of microglial cells on a fibronectin-coated surface was examined. Figure 2 shows representative images captured for a spreading microglial cell (Figure 2A), and the same images modified for cell surface area calculations (Figure 2B). Individual microglia were analysed for the time taken to initiate spreading after attaching to the fibronectin-coated surface, and the subsequent speed of spreading, if initiation was successful. The spreading profiles of TG WT and NTG (WT) microglia were similar, and consisted of comparable percentages of cells that spread immediately, after a delay of $100 \mathrm{~s}$ before initiating spreading, or that were stationary, i.e. that failed to spread (immediate: $72.2 \pm 20.0 \%$ in TG WT versus $60.7 \pm$ $13.0 \%$ in NTG (WT) cells; delayed: $11.1 \pm 11.1 \%$ in TG WT versus $6.3 \pm 6.3 \%$ in NTG (WT) cells; stationary: $16.7 \pm 9.6 \%$ in TG WT versus $33.0 \pm 13.0 \%$ in NTG (WT) cells, Figure $2 \mathrm{C}$ ). In contrast, the spreading profiles of TG G93A and NTG (G93A) microglia differed significantly. TG G93A microglia had a lower percentage of immediate and a higher percentage of stationary cells when compared to NTG (G93A) microglia (immediate: $43.7 \pm 8.9 \%$ in TG G93A versus $73.5 \pm$ $7.1 \%$ in NTG (G93A) cells; $\mathrm{p}=0.0195$, Student's t test; delayed: $18.3 \pm 7.1 \%$ in TG G93A versus $11.5 \pm 6.3 \%$ in NTG (G93A) cells; stationary: $38.0 \pm 9.5 \%$ in TG G93A versus $12.8 \pm 6.7 \%$ in NTG (G93A) cells; $\mathrm{p}=$ 0.0483 , Student's t test, Figure 2D).

\section{Spreading and migration speeds are unaltered in TG G93A microglia but are increased in TG WT cells}

To further investigate if the reduced expression levels of integrin $\beta-1$ by TG G93A microglia affected microglial spreading and migration, the speeds of spreading and migration were measured. While the ability to spread on fibronectin-coated surface was impaired in the TG G93A microglia (Figure 2D), the speed of spreading of those TG G93A microglia that did spread was not different from that of spreading NTG (G93A) microglia $\left(8.6 \pm 1.3 \mu \mathrm{m}^{2} / \mathrm{s}\right.$ for TG G93A versus $10 \pm 1.3 \mu \mathrm{m}^{2} / \mathrm{s}$ for NTG (G93A) microglia, Figure 3A). Interestingly, TG WT microglia that did spread had a greater speed of spreading compared to NTG (WT), albeit not statistically significant $\left(26.6 \pm 4.3 \mu \mathrm{m}^{2} / \mathrm{s}\right.$ for TG WT versus $16.2 \pm 3.3 \mu \mathrm{m}^{2} / \mathrm{s}$ for NTG (WT) microglia; $\mathrm{p}=0.0693$, Student's t test, Figure 3A). To investigate if the spreading impairment of TG G93A microglia could affect migration, the speed of random migration of NTG (G93A), TG G93A, NTG (WT) and TG WT microglia on genotype-matched astrocytic monolayers was measured. TG G93A microglia had similar speed of migration as NTG (G93A) microglia $(1.9 \pm 0.3 \mu \mathrm{m} / \mathrm{min}$ for TG G93A versus $1.6 \pm 0.2 \mu \mathrm{m} / \mathrm{min}$ for NTG (G93A) microglia). Again, TG WT cells showed increased speed of migration when compared to NTG (WT) microglia $(1.9 \pm 0.1 \mu \mathrm{m} / \mathrm{min}$ for TG WT versus $1.1 \pm 0.1 \mu \mathrm{m} / \mathrm{min}$ for NTG (WT) cells, $\mathrm{p}=0.0004$, Student's t test, Figure 3B). Directional migration of NTG (G93A), TG G93A, NTG (WT) and TG WT microglia towards the chemoattractant MCP-1 was also investigated (Additional file 2), without detectable differences in distance migrated between the cells of the four genotypes (data not shown). 

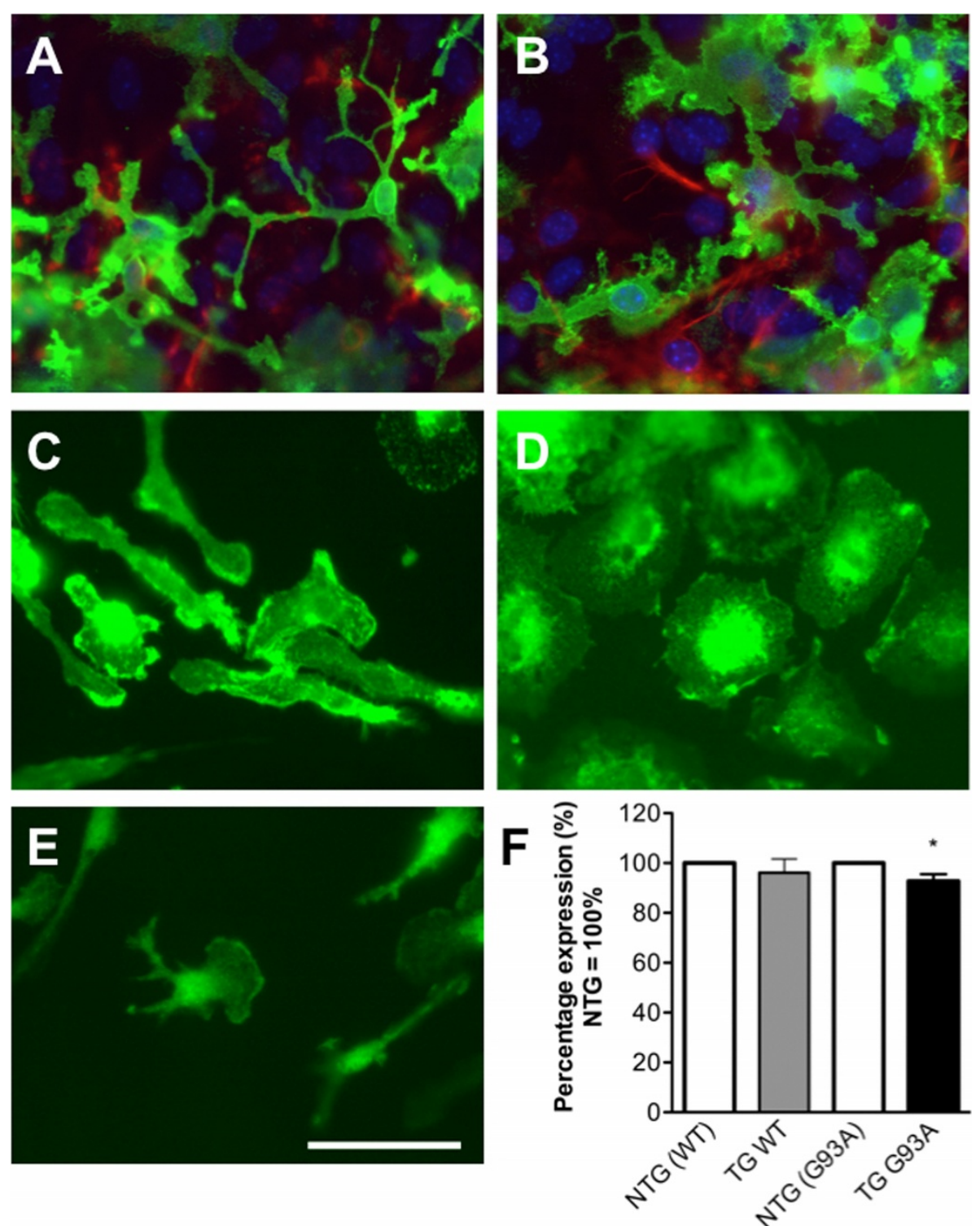

Figure 1 Microglial culture purity and reduced expression of integrin $\beta$ - 1 by TG G93A microglia. (A and B) Immunostaining of representative mixed glial cultures used to purify microglia. The cultures were stained with anti-CD11b (green) and anti-GFAP (red) antibodies to show microglia in green and astrocytes in red; nuclei were stained with Hoechst (blue). (C and D) Immunostaining with anti-F4/80 antibody of purified resting (C) and activated with lipopolysaccharide (D) microglia. (E) Immunostaining of purified microglia with isotype control antibody shows residual non-specific fluorescence with the isotype-matched antibody. Scale bar $=50 \mu \mathrm{m}$. (F) Cell surface integrin $\beta-1$ expression levels on NTG (WT), TG WT, NTG (G93A) and TG G93A microglia. Data are presented as mean \pm SEM; Student's $t$ test, ${ }^{*} p=0.0493$ versus NTG (G93A) cells, $n=14$ TG G93A and nine NTG (G93A) mice from four litters, five TG WT and five NTG (WT) mice from two litters.

\section{Reduced ability of TG WT and TG G93A microglia to} phagocytose apoptotic neuronal cell debris

To establish if the overexpression of SOD1 in microglia altered the ability to phagocytose apoptotic cell debris, the phagocytosis of apoptotic murine neuronal cell (NSC34) debris by microglia was investigated. Microglial cells, incubated with apoptotic NSC34 neuronal cell debris, labelled with a membrane dye VybrantDiI, were extensively washed to remove any unphagocytosed material and immunostained with anti-integrin $\beta-1$ antibody to delineate the plasma membrane. Figure 4 presents the scoring scale used to score the level of phagocytosis (Figure 4A) and representative immunostaining pictures of NTG (G93A) and TG G93A microglia with the phagocytosed material (Figure 4B). The percentage of microglia with medium (score 4) to high (score 6) loads of phagocytic material were compared between the four genotypes. TG G93A and TG WT 

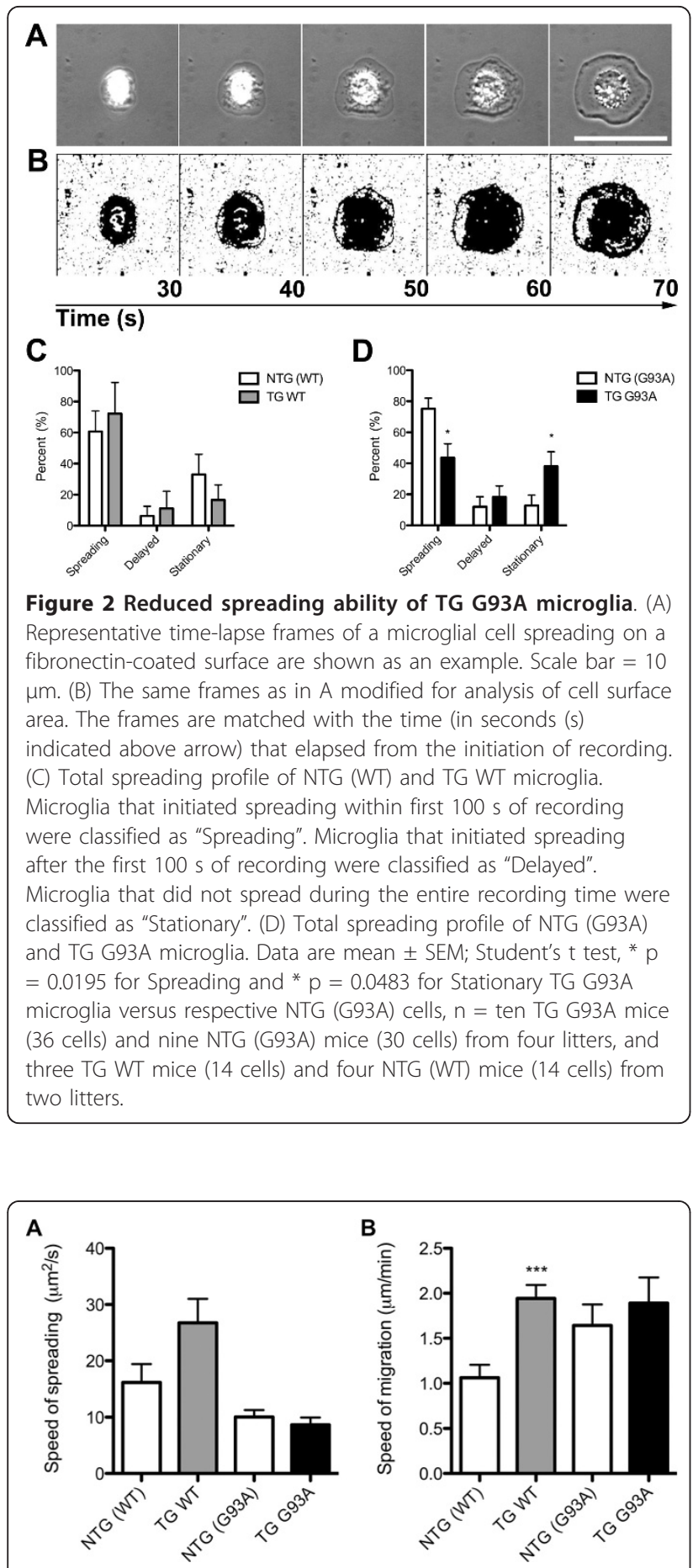

Figure 3 Spreading and migration speeds of TG G93A and TG WT microglia. (A) Speed of spreading $\left(\mu \mathrm{m}^{2} / \mathrm{s}\right)$ of NTG (WT), TG WT, NTG (G93A) and TG G93A microglia, $n=$ three TG WT mice (12 cells) and three NTG (WT) mice (ten cells) obtained from two litters, and ten TG G93A mice (15 cells) and nine NTG (G93A) mice (20 cells) from four litters. (B) Speed of migration ( $\mu \mathrm{m} / \mathrm{min}$ ) of NTG (WT), TG WT, NTG (G93A) and TG G93A microglia on genotype-matched astrocytic monolayers. Data are mean \pm SEM; Student's t test, ${ }^{* * *} p$ $=0.0004$ versus NTG (WT) microglia, $\mathrm{n}=$ three TG WT mice (ten cells) and three NTG (WT) mice (ten cells) from two litters. microglia had a significantly lower percentage of microglia scoring from 4 to 6 than the respective NTG cells $(13.0 \pm 1.3 \%$ for TG G93A, $16.5 \pm 1.9 \%$ for TG WT, $28.6 \pm 1.8 \%$ for NTG $($ G93A) and $26.9 \pm 2.8 \%$ for NTG (WT) microglia, $\mathrm{p}=0.0001$, Student's t test, Figure 4C).

\section{Reduced intracellular calcium release in TG WT and TG} G93A microglia following extracellular ATP stimulation To investigate whether the overexpression of SOD1 in microglia affected intracellular calcium changes following a pro-inflammatory stimulus, microglial intracellular calcium concentration $\left(\left[\mathrm{Ca}^{2+}\right]_{\mathrm{i}}\right)$ was measured before, during, and after stimulation with $10 \mu \mathrm{M}$ ATP. Stimulation with ATP increased $\left[\mathrm{Ca}^{2+}\right]_{\mathrm{i}}$ and withdrawal of ATP resulted in a steady reduction of the $\left[\mathrm{Ca}^{2+}\right]_{\mathrm{i}}$ to almost baseline levels in microglia of all genotypes (Figure 5A and $5 \mathrm{~B})$. Microglia of all four genotypes had comparable baseline $\left[\mathrm{Ca}^{2+}\right]_{\mathrm{i}}: 0.16 \pm 0.01 \mu \mathrm{M}$ for NTG (G93A), 0.14 $\pm 0.01 \mu \mathrm{M}$ for TG G93A, $0.12 \pm 0.01 \mu \mathrm{M}$ for NTG (WT) and $0.13 \pm 0.01 \mu \mathrm{M}$ for TG WT. The first $10 \mathrm{~s}$ of ATP stimulation resulted in an initial rapid increase of $\left[\mathrm{Ca}^{2+}\right]_{\mathrm{i}}$ in NTG microglia, followed by a steady reduction of $\left[\mathrm{Ca}^{2+}\right]_{\mathrm{i}}$ during the remaining $50 \mathrm{~s}$ of ATP challenge. However, TG microglia displayed a different pattern of $\left[\mathrm{Ca}^{2+}\right]_{i}$ changes; the initial peak in $\left[\mathrm{Ca}^{2+}\right]_{i}$ was absent in both TG G93A and TG WT microglia (Figure $5 \mathrm{~A}$ and $5 \mathrm{~B}$ ). The first $10 \mathrm{~s}$ of ATP challenge only moderately increased the $\left[\mathrm{Ca}^{2+}\right]_{\mathrm{i}}$ in TG G93A and TG WT microglia. This $\left[\mathrm{Ca}^{2+}\right]_{i}$ was maintained until ATP was withdrawn. The area-under-the-curve (AUC) calculations quantified this pattern of $\left[\mathrm{Ca}^{2+}\right]_{i}$ changes, and showed areas of $19.1 \pm 1.8 \mu \mathrm{M}^{*}$ s for NTG (G93A) versus 14.4 $\pm 2.2 \mu \mathrm{M}^{*}$ s for TG G93A microglia, $\mathrm{p}=0.0176$, Student's t test, and $14.6 \pm 1.5 \mu \mathrm{M}^{*} \mathrm{~s}$ for NTG (WT) versus $11.9 \pm 1.6 \mu \mathrm{M}^{*} \mathrm{~s}$ for TG WT cells, not significantly different (Figure $5 \mathrm{C}$ ). The highest value of $\left[\mathrm{Ca}^{2+}\right]_{\mathrm{i}}$ was significantly smaller in TG G93A and TG WT microglia when compared to respective NTG cells and was $0.28 \pm 0.02 \mu \mathrm{M}$ for TG G93A versus $0.39 \pm 0.03$ $\mu \mathrm{M}$ for NTG (G93A) cells, $\mathrm{p}=0.003$, Student's t test, and $0.24 \pm 0.03 \mu \mathrm{M}$ for TG WT versus $0.37 \pm 0.05 \mu \mathrm{M}$ for NTG (WT) microglia, $\mathrm{p}=0.0123$, Student's t test (Figure 5D). Interestingly, stimulation of microglia with a high concentration of ATP (1 mM for $1 \mathrm{~min})$ reversed this initial reduced response in $\left[\mathrm{Ca}^{2+}\right]_{\mathrm{i}}$ changes, but only in TG G93A microglia (Additional file 3).

\section{Discussion}

In the present study we compared an array of functional properties of transgenic microglia overexpressing wild type SOD1 or mutant SOD1 G93A to those of nontransgenic control cells.

Integrin $\beta-1$ (fibronectin receptor $\beta$ ) is involved in diverse cellular functions including cellular adhesion to 


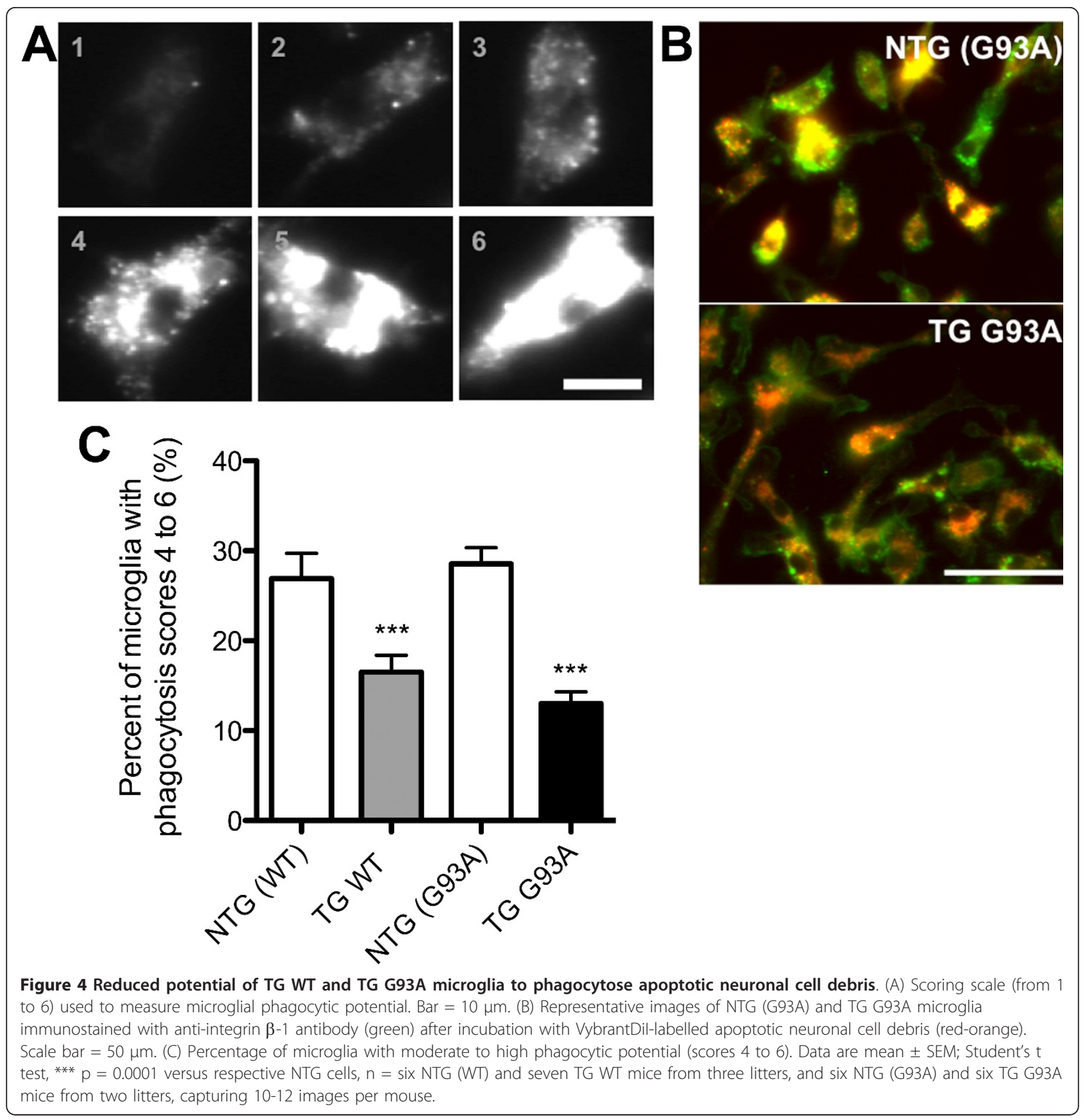

extracellular matrix, focal adhesion, migration, actin polymerisation/assembly, and regulation of the cell cycle [48-50]. We observed only modestly reduced levels of integrin $\beta-1$ on TG G93A microglia when compared to the levels on NTG (G93A) cells. Also, the small sample size of TG WT and NTG (WT) microglia may have prevented the detection of differences in integrin $\beta-1$ expression levels in this cell population. Nonetheless, reduced levels of integrin $\beta-1$ on TG G93A microglia could lead to impaired adhesion, migration, phagocytosis, and proliferation. To test whether the former three functions were altered in TG G93A microglia, we examined microglial spreading on fibronectin-coated surface, migration on genotype-matched astrocytic monolayers, and phagocytosis of apoptotic neuronal cell debris. We observed that although expression of integrin $\beta-1$ was marginally reduced, and spreading ability impaired, in TG G93A cells, these changes did not affect the migration of TG G93A microglia, as the cells were capable of migrating on genotype-matched astrocytes at 


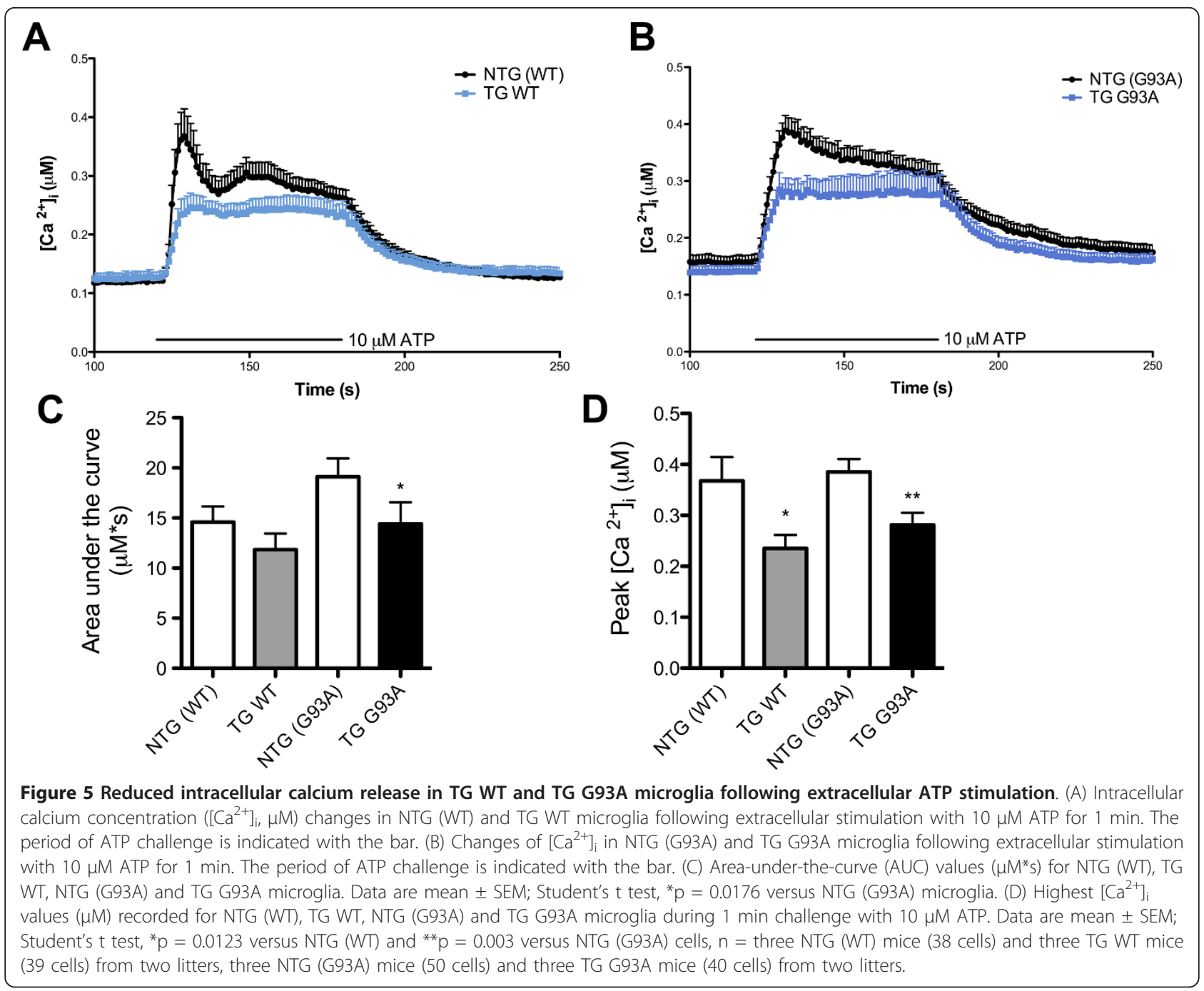

the same speed as NTG (G93A) cells. This observation may indicate that the slightly reduced levels of integrin $\beta-1$ expression on TG G93A microglia may have no significant impact on the cellular spreading and migration, or that additional receptor-ligand interactions compensate for reduced integrin $\beta-1$ expression and impaired spreading ability.

Our study also showed that overexpression of both transgenes affected microglial phagocytosis of apoptotic neuronal cell debris, an effect presumably unrelated to the reduced integrin $\beta-1$ expression. Microglial uptake of degenerating motor neuronal debris has been shown in vivo after injection of toxin ricin into rat facial nerve [51]. Microglia were the primary cells to clear neuronal debris from degenerating neurons during development or after neuronal injury in adult animals [52,53]. Efficient clearance of SOD1 aggregates significantly improved the disease course in ALS model mice [54]. Moreover, persistence of destroyed tissue debris was capable of inducing and perpetuating CNS tissue inflammation $[55,56]$. Thus, the impaired ability to phagocytose apoptotic neuronal debris by TG WT, and more so by TG G93A, microglia may contribute to disease exacerbation.

Overexpression of SOD1 G93A as well as wild type $S O D 1$ altered the intracellular $\mathrm{Ca}^{2+}$ responses to extracellular ATP stimulation. Cellular responses to extracellular nucleotides are mediated via cell surface P2 purinoreceptors, now classified as metabotropic (P2Y) receptors that mediate signalling through G-proteins, and ionotropic (P2X) receptors that are directly coupled to non-selective cationic receptors allowing for influx of $\mathrm{Ca}^{2+}$ and $\mathrm{Na}^{+}$and efflux of $\mathrm{K}^{+}$[57]. Physiologically, ATP-induced signalling attracts microglia to the site of injury or cellular damage resulting in microglial activation [42,58]. Microglia express $\mathrm{P}_{2}, \mathrm{P}_{4} \mathrm{X}_{7}, \mathrm{P}_{2} \mathrm{Y}_{1}, \mathrm{P}_{2} \mathrm{Y}_{2}$, $\mathrm{P}^{2} \mathrm{Y}_{6}$ and $\mathrm{P}_{2} \mathrm{Y}_{12}$ receptors [59-62], and their stimulation initiates release of $\mathrm{Ca}^{2+}$ from intracellular stores. In 
addition, stimulation through $\mathrm{P} 2 \mathrm{X}$ receptors induces non-selective ion exchange that may result is microglial depolarisation [63]. Microglia from SOD1 G93A-overexpressing ALS mouse models were found to have an increased expression of $\mathrm{P}_{2} \mathrm{X}_{4}, \mathrm{P}_{2} \mathrm{X}_{7}$ and $\mathrm{P} 2 \mathrm{Y}_{6}$ receptors and reduced ability to hydrolyse extracellular ATP [64]. Moreover, prolonged (3 to 24 hours) stimulation with $30 \mu \mathrm{M}$ ATP induced higher levels of COX-2 expression and elevated production of the pro-inflammatory cytokine TNF- $\alpha$ in SOD1 G93A microglia compared to NTG cells [64], demonstrating the exaggerated proinflammatory phenotype of SOD1 G93A microglia. However, during our experiments, short (1 min) stimulation of microglia with $10 \mu \mathrm{M}$ ATP demonstrated that microglia overexpressing SOD1 G93A, or wild type $S O D 1$, had a reduced initial increase in intracellular $\mathrm{Ca}^{2}$ ${ }^{+}$when compared to that in NTG cells, which suggests an alteration of calcium release from the endoplasmic reticulum. Thus, higher ATP levels, and/or prolonged stimulation by the nucleotide, may be necessary in order to elicit physiologically relevant responses from SOD1overexpressing microglia, although overstimulation leads to exaggerated pro-inflammatory response from TG G93A microglia (Reference [26] and Additional file 3).

To summarise, it is well characterized that in ALS animal models activated microglia contribute to neurodegeneration through production of neurotoxic compounds following activation [13,64] and acquisition of an exaggerated inflammatory phenotype $[24,26]$. Here, we show evidence that SOD1 transgenic microglia have a reduced capacity to sense tissue disturbances under resting conditions. The affected functions in resting SOD1 microglia are a reduced ability to phagocytose apoptotic neuronal cell debris and an attenuated response to extracellular ATP stimulation. We propose that resting state microglia overexpressing SOD1 G93A, or wild type $S O D 1$, may contribute to disease pathogenesis through loss of efficient tissue-protective functions. Also, caution must be used when ascribing alterations in microglial behaviour to mutant SOD1 expression. Our results indicate that wild-type $S O D 1$ overexpression can alter some properties of microglia and should be an obligatory control in all experiments.

\section{Conclusions}

Microglia, the macrophages of the brain, are known to play vital physiological roles in maintaining healthy CNS tissue architecture and function. In ALS pathogenesis, microglia contribute to disease progression through continuous activation and secretion of multiple pro-inflammatory and neurotoxic mediators. Here, we present the novel findings that resting-state microglia overexpressing wild type or mutant SOD1 transgenes have reduced physiologic responses of apoptotic neuronal cell clearance and release of $\mathrm{Ca}^{2+}$ from intracellular stores upon ATP stimulation. Our findings indicate that transgenic SOD1 microglia may require higher concentrations of stimulatory factors to elicit physiologicallyrelevant functions, indicating reduced neuroprotective behaviour of TG microglia.

\section{Methods}

\section{Primary microglial culture preparation}

All animals were handled in accordance with the guidelines of the Animals (Scientific Procedures) Act 1986. Microglia were purified from mixed glial cultures as described [26]. Briefly, the cortices of neonatal (1-2 days old) human mutant SOD1 G93A transgenic mice, human wild type $S O D 1$ transgenic mice, and their nontransgenic (NTG) littermates (NTG (G93A) and NTG (WT), respectively) were stripped of meninges, washed and triturated in Hank's balanced salt solution with $\mathrm{Ca}^{2}$ ${ }^{+} / \mathrm{Mg}^{2+}$ containing $0.04 \%$ trypsin (Sigma), $0.1 \mathrm{mg} / \mathrm{ml} \mathrm{col-}$ lagenase (Calbiochem) and $0.05 \mathrm{mg} / \mathrm{ml}$ DNaseI (Sigma). After trituration, the single cells were pelleted and plated in complete medium [Dulbecco's modified Eagle's medium (DMEM; Cambrex Bioscience), 10\% heat-inactivated foetal calf serum (FCS; BioSera), 100 units/ml penicillin and $100 \mathrm{mg} / \mathrm{ml}$ streptomycin (Gibco, Invitrogen)] at 60000 cells $/ \mathrm{cm}^{2}$ on poly-L-lysine (Sigma) coated coverslips. For the purification of microglia, the confluent cultures were subjected to shaking and mild trypsinisation $[13,65]$, which resulted in microglial cultures of more than $90 \%$ purity.

\section{Immunostaining}

The cells were washed with phosphate-buffered saline (PBS), fixed with $4 \%$ paraformaldehyde for $15 \mathrm{~min}$ and permeabilised with $0.1 \%$ Triton $\mathrm{X}-100$. Non-specific binding was blocked with 5\% FCS in PBS for $30 \mathrm{~min}$. The cells were incubated with rat anti-mouse CD11b (Serotec), rat anti-mouse F4/80 (Serotec), or isotype control (Serotec) primary antibodies in blocking buffer at room temperature. After washing with PBS, cells were incubated with the goat anti-rat-fluorescein isothiocyanate (FITC) secondary antibody (Serotec) and, where needed, with conjugated Cy3-anti-glial fibrillary acidic protein (GFAP) antibody (Sigma) in blocking buffer. After washing, the nuclei were stained with $0.2 \mu \mathrm{g} /$ $\mathrm{ml}$ Hoechst 33342 (Intergen) solution for $1 \mathrm{~min}$ and the coverslips mounted on glass sides in mounting medium (50\% glycerol in PBS).

\section{Measurement of integrin $\beta$-1 expression}

Microglia isolated from mixed glial cultures were deposited into U-bottomed 96-well plates at 20000 cells/well, washed in $200 \mu \mathrm{l}$ fluorescence activated cell sorting (FACS) buffer (PBS containing $0.2 \% \mathrm{w} / \mathrm{v}$ bovine serum 
albumin (BSA) and $0.1 \% \mathrm{w} / \mathrm{v}$ sodium azide) and incubated with conjugated FITC-anti-mouse integrin $\beta-1$ (Biolegend) or FITC-isotype control antibody (Biolegend) in FACS buffer for $20 \mathrm{~min}$ on ice. Cell-associated mean fluorescence intensity (MFI) was detected using a BD FACSort (Becton Dickinson). The acquired geometric mean fluorescence values of isotype antibodystained cells were subtracted from those of the FITCintegrin $\beta-1$ stained cells. The resultant values were then compared between respective NTG and TG cells, after counting the mean MFI of NTG cells as $100 \%$ (Additional file 1).

\section{Spreading assay}

Isolated microglia were added to an imaging chamber containing a coverslip coated with $5 \mu \mathrm{g} / \mathrm{ml}$ of bovine fibronectin (Calbiochem) as a substrate. Cells were visualized under a $\times 40$ oil immersion objective heated to $37^{\circ} \mathrm{C}$ with an objective heater (Bioptechs, Intracel) and the spreading of individual cells in phase contrast recorded by a timelapse automation, using Openlab 3.7.1 software. After the cells touched the coated coverslip, the frames were captured every $5 \mathrm{~s}$ for a maximum of $15 \mathrm{~min}$. The captured frames were analysed with ImageJ plugins to obtain cell surface area values for every frame. The cells were classified as "spreading" if they initiated cell surface area expansion (spreading) within first $100 \mathrm{~s}$ of recording. The cells were classified as "delayed" if they initiated cell surface area expansion after the first $100 \mathrm{~s}$ of recording. The cells were classified as "stationary" if they did not initiate cell surface area increase during the entire recording time. For every spreading cell, the cell surface area values of the expanding (spreading) phase were plotted against the time taken to reach those values, and the speed of spreading was deduced from this relationship using GraphPad Prism 5.0 linear regression analysis.

\section{Migration assay}

Mixed glial cultures in T25 flasks (Croning) were placed in a microscope chamber equilibrated to $37^{\circ} \mathrm{C}, 5 \% \mathrm{CO}_{2}$, (LEICA Microsystems AF6000LX microscope with environmental control) for time-lapse recordings. A $\times 10$ objective field of cells was captured every 3 min for $15 \mathrm{~h}$. Using phase contrast microscopy, small phase-bright amoeboid and ramified microglia were easily visible on top of the larger astrocytes that formed a confluent monolayer. The captured frames were loaded into ImageJ software as one stack, and microglia were chosen at random from each field of view and analysed for the distance migrated.

\section{Phagocytosis of neuronal cell debris}

NSC34 cells (a murine motor neuronal cell line [66]) were labelled with a membrane dye [1, 1'-dioctadecyl3,3,3',3'-tetramethylindocarboxyanine perchlorate
(VybrantDiI) with an emission wavelength in red-orange spectrum (Invitrogen)] according to the manufacturer's protocol. The cells were then incubated for $48 \mathrm{~h}$ in serum free DMEM to induce apoptosis through oxidative stress [67], at which point cell death had occurred in $90 \%$ of cells. The labelled NSC34 cell debris was collected and frozen at $-80^{\circ} \mathrm{C}$. Microglial cells plated on poly-L-lysine (Sigma) -coated $13 \mathrm{~mm}$ coverslips were incubated with $500 \mu \mathrm{l}$ of labelled NSC34 cell debris for $21 \mathrm{~h}$ at $37^{\circ} \mathrm{C}$. Microglia were extensively washed with $\mathrm{PBS}$ to remove any unphagocytosed debris, and immunostained with conjugated FITC-anti-mouse integrin $\beta-1$ (Biolegend) antibody. Using fluorescence microscopy, an operator blinded to the genotypes of microglial cells scored the cells according to the uptake of VybrantDiIlabelled material on a scale from 1 to 6 (Figure 4A).

\section{Measurement of intracellular calcium concentration}

The measurements of microglial intracellular free calcium were carried out according to a previously published method $[68,69]$. The cells were pre-incubated with the membrane-permeable ester form of the highaffinity ratiometric calcium dye Fura-2 AM $(10 \mu \mathrm{M})$ for $15 \mathrm{~min}$ and allowed to de-esterify for $30 \mathrm{~min}$ at room temperature $\left(25^{\circ} \mathrm{C}\right)$. The cells were placed in a recording chamber $(3 \mathrm{ml})$, which was continuously perfused (10 $\mathrm{ml} / \mathrm{min}$ ) with a standard extracellular solution containing: HEPES $11.6 \mathrm{mM}, \mathrm{Na}^{+} 129.1 \mathrm{mM}, \mathrm{Cl}^{-} 143.8 \mathrm{mM}, \mathrm{K}^{+}$ $5.9 \mathrm{mM}, \mathrm{Mg}^{2+} 1.2 \mathrm{mM}, \mathrm{Ca}^{2+} 3.2 \mathrm{mM}$, and glucose 10.0 $\mathrm{mM}$, at $\mathrm{pH}=7.3$. Fluorescent images were obtained using $\times 40$ objective on an Axiovert 200 microscope (Carl Zeiss) fitted with a C9100 electron multiplier CCD camera (Hamamatsu Photonics) at 345/380 nm excitation (Polychrome IV, Till Photonics) and $510 \mathrm{~nm}$ emission filters. Devices and shutters were controlled by Openlab 3.7.1 software, which provided image acquisition and continuous online $\mathrm{Ca}^{2+}$ concentration calculation by custom scripting at $1 / \mathrm{s}$. The regions of interest were defined over perinuclear/cytoplasmic regions of microglia and changes in fluorescence ratios (345/380) recorded at rest and during stimulation with specified concentrations of ATP, which was applied with a custom-made solution applicator with a solution exchange time of $\sim 100 \mathrm{~ms}$ in the area of view. Background fluorescence subtraction was used and calcium concentration calculated according to Grynkiewicz [70].

\section{Statistical analysis}

Due to inherent differences between the two transgenic colonies of mice (transgenic SOD1 G93A and transgenic $S O D 1$ wild type) that we observed in our past experiments, we limited our statistical comparisons to measure differences between NTG and TG cells within colonies, and not between colonies. Data were analysed 
using GraphPad Prism 5.0 software. All data that fitted a normal distribution were analysed using Student's $t$ test. Data that did not fit a normal distribution were transformed using $\mathrm{Y}=\log (\mathrm{Y})$ transformation.

\section{Additional material}

Additional file 1: Calculation of percent expression of integrin $\beta-1$ on primary microglia. (A) A representative example of flow cytometry histograms for NTG (G93A) and TG G93A microglia with FITC-isotype antibody or FITC-anti-integrin $\beta-1$ antibody is presented. Each histogram contains data on the geometric mean fluorescence $(\mathrm{Gm})$, coefficient of variance (CV), marker position (0-430), number and percentage of cells under the marker. (B) An overlay of histograms from another independent experiment represents the FITC signal distribution for FITCisotype antibody stained TG G93A microglia (filled curve), FITC-antiintegrin $\beta-1$ antibody stained TG G93A microglia (curve with dashed line) and FITC-anti-integrin $\beta-1$ antibody stained NTG (G93A) microglia (curve with solid line). The horizontal axis in (A) and (B), FL-1-H, is the detected signal intensity of FITC on a logarithmic scale. An example of percentage expression calculation is given below: 1. Under the marker M1 over 95\% of the cells are detected, with the Gm for NTG (G93A) microglia of 11.11 with specific antibody, and 4.54 with isotype antibody. 2. For these NTG (G93A) microglia the integrin $\beta-1$ expression is $11.11-4.54=\mathbf{6 . 5 7}$, and for TG G93A cells the integrin $\beta-1$ expression is $10.62-4.93=\mathbf{5 . 6 9}$. These expression values are then converted to values on a linear scale. The values for NTG (G93A) are set as 100\% expression. The values from TG (G93A) then converted to percent expression with respect to $100 \%$ of NTG (G93A) cells.

\section{Additional file 2: Migration of TG WT and TG G93A microglia} towards the chemoattractant MCP-1: (A) A representative image of microglial cells on fibronectin-coated coverglass overlaying a Dunn migration chamber with cells facing the chamber. The image was taken on the LEICA Microsystems AF6000LX microscope on a x10 objective, with environmental control to maintain the slide at $37^{\circ} \mathrm{C}$. To record migration, images were taken every 3 minutes for 1 hour using Leica software. At the top of the picture is the edge of the outer well, which was filled with medium containing MCP-1. The lower edge is the inner well containing normal medium. Scale bar $=50 \mu \mathrm{m}$. (B) An example of analysis of migrated distance represents vector diagrams of cell displacement recorded one hour after setting up the Dunn chamber. Each point represents the position of a cell, which at time 0 is positioned at the intersection of the two axes. The $X$ and $Y$ axes are in $\mu \mathrm{m}$. Labels: FIB - indicates the coverglass was coated with fibronectin, MCP-1 monocyte chemoattractant protein-1, 300 - indicates $300 \mathrm{ng} / \mathrm{ml}$ concentration of MCP-1.

Additional file 3: Stimulation of TG WT and TG G93A microglia with $1 \mathrm{mM}$ ATP. (A) Intracellular calcium concentration $\left(\left[\mathrm{Ca}^{2+}\right]_{i}, \mu \mathrm{M}\right)$ changes in NTG (WT) and TG WT microglia following extracellular stimulation with $1 \mathrm{mM}$ ATP for $1 \mathrm{~min}$. The period of ATP challenge is indicated with the bar. (B) Changes of $\left[\mathrm{Ca}^{2+}\right]_{i}$ in NTG (G93A) and TG G93A microglia following extracellular stimulation with $1 \mathrm{mM}$ ATP for $1 \mathrm{~min}$. The period of ATP challenge is indicated with the bar. (C) Area-under-the-curve (AUC) values $\left(\mu M^{*}\right.$ s) for NTG (WT), TG WT, NTG (G93A) and TG G93A microglia. Data are mean \pm SEM; Student's $t$ test, ${ }^{*} p=0.0201$ versus NTG (WT) microglia. (D) $\left[\mathrm{Ca}^{2+}\right]_{i}$ values $(\mu \mathrm{M})$ recorded for NTG (WT), TG WT, NTG (G93A) and TG G93A microglia at $130 \mathrm{~s}$ of recording (10 s after initiation of $1 \mathrm{mM}$ ATP challenge). Data are mean \pm SEM; Student's $t$ test, ${ }^{*} p=0.0381$ versus NTG (WT) and ${ }^{*} p=0.0015$ versus NTG (G93A) cells, $n$ $=$ three NTG (WT) mice (14 cells) and three TG WT mice (18 cells) from two litters, three NTG (G93A) mice (43 cells) and three TG G93A mice (38 cells) from two litters.

\section{Acknowledgements}

This study was supported by the Wellcome Trust, Medical Research Council, Motor Neuron Disease Association, University of Sheffield (Grave's
Fellowship) and by British Medical Association (Vera Down Award). JG was supported by the Deutsche Forschungsgemeinschaft (DFG grant GR 1578 21). The authors are thankful to Dr. Benjamin Dubin-Thaler for his helpful advice regarding the spreading assay.

\section{Author details}

'Department of Medicine, University of Colorado Denver School of Medicine, CO, USA. ${ }^{2}$ The Academic Neurology Unit, Sheffield Institute for Translational Neuroscience (SITraN), 385A Glossop Road, University of Sheffield, S10 2HQ, UK. ${ }^{3}$ Hans Berger Department of Neurology, University Hospital Jena, Jena, Germany. ${ }^{4}$ MRC Centre for Neurodegeneration Research, Institute of Psychiatry, King's College London, London, UK. ${ }^{5}$ Department of Infection and Immunity, School of Medicine and Biomedical Sciences, University of Sheffield, UK.

\section{Authors' contributions}

SAS performed the immunostaining, flow cytometry, spreading, and calcium concentration measurement studies, as well as assisted with the manuscript preparation. DJB performed the migration assays and contributed to the manuscript preparation. SCB helped with the statistical analysis and manuscript preparation. KJDV designed the spreading assay, wrote the Openlab 3.7.1 automation for time-lapse imaging, and assisted with manuscript preparation. JG developed the assay for ATP stimulation and intracellular calcium concentration measurements and the analysis of the obtained results, and helped with the manuscript preparation. PJS was the grant holder and PNM and PJS supervised the study and prepared the manuscript. All authors read and approved the final manuscript.

\section{Competing interests}

The authors declare that they have no competing interests.

Received: 8 May 2011 Accepted: 23 September 2011

Published: 23 September 2011

\section{References}

1. Brownell B, Oppenheimer D, Hughes J: The central nervous system in motor neurone disease. J Neurol Neurosurg Psychiatry 1970, 33:338-357.

2. Rowland L: Diagnosis of amyotrophic lateral sclerosis. J Neurol Sci 1998, 160(Suppl 1):S6-24.

3. Shaw P: Molecular and cellular pathways of neurodegeneration in motor neurone disease. J Neurol Neurosurg Psychiatry 2005, 76:1046-1057.

4. Bruijn L, Miller T, Cleveland D: Unraveling the mechanisms involved in motor neuron degeneration in ALS. Annu Rev Neurosci 2004, 27:723-749.

5. Rosen D, Siddique T, Patterson D, Figlewicz D, Sapp P, Hentati A, Donaldson D, Goto J, O'Regan J, Deng H: Mutations in Cu/Zn superoxide dismutase gene are associated with familial amyotrophic lateral sclerosis. Nature 1993, 362:59-62.

6. Andersen $P$, Nilsson P, Keränen $M$, Forsgren L, Hägglund J, Karlsborg M, Ronnevi L, Gredal O, Marklund S: Phenotypic heterogeneity in motor neuron disease patients with CuZn-superoxide dismutase mutations in Scandinavia. Brain 1997, 120(Pt 10):1723-1737.

7. Haverkamp L, Appel V, Appel S: Natural history of amyotrophic lateral sclerosis in a database population. Validation of a scoring system and a model for survival prediction. Brain 1995, 118(Pt 3):707-719.

8. Bruijn L, Becher M, Lee M, Anderson K, Jenkins N, Copeland N, Sisodia S, Rothstein J, Borchelt D, Price D, Cleveland D: ALS-linked SOD1 mutant G85R mediates damage to astrocytes and promotes rapidly progressive disease with SOD1-containing inclusions. Neuron 1997, 18:327-338.

9. Gurney M, Pu H, Chiu A, Dal Canto M, Polchow C, Alexander D, Caliendo J, Hentati A, Kwon Y, Deng H: Motor neuron degeneration in mice that express a human $\mathrm{Cu}, \mathrm{Zn}$ superoxide dismutase mutation. Science 1994, 264:1772-1775.

10. Wong P, Borchelt D: Motor neuron disease caused by mutations in superoxide dismutase 1. Curr Opin Neurol 1995, 8:294-301.

11. Clement A, Nguyen M, Roberts E, Garcia M, Boillée S, Rule M, McMahon A, Doucette W, Siwek D, Ferrante R, et al: Wild-type nonneuronal cells extend survival of SOD1 mutant motor neurons in ALS mice. Science 2003, 302:113-117.

12. Boillée S, Yamanaka K, Lobsiger C, Copeland N, Jenkins N, Kassiotis G, Kollias G, Cleveland D: Onset and progression in inherited ALS 
determined by motor neurons and microglia. Science 2006, 312:1389-1392.

13. Beers D, Henkel J, Xiao Q, Zhao W, Wang J, Yen A, Siklos L, McKercher S, Appel S: Wild-type microglia extend survival in PU.1 knockout mice with familial amyotrophic lateral sclerosis. Proc Natl Acad Sci USA 2006, 103:16021-16026.

14. Almer G, Teismann P, Stevic Z, Halaschek-Wiener J, Deecke L, Kostic V, Przedborski S: Increased levels of the pro-inflammatory prostaglandin PGE2 in CSF from ALS patients. Neurology 2002, 58:1277-1279.

15. Henkel J, Engelhardt J, Siklós L, Simpson E, Kim S, Pan T, Goodman J, Siddique T, Beers D, Appel S: Presence of dendritic cells, MCP-1, and activated microglia/macrophages in amyotrophic lateral sclerosis spinal cord tissue. Ann Neurol 2004, 55:221-235.

16. Poloni M, Facchetti D, Mai R, Micheli A, Agnoletti L, Francolini G, Mora G, Camana C, Mazzini L, Bachetti T: Circulating levels of tumour necrosis factor-alpha and its soluble receptors are increased in the blood of patients with amyotrophic lateral sclerosis. Neurosci Lett 2000, 287:211-214

17. Turner M, Cagnin A, Turkheimer F, Miller C, Shaw C, Brooks D, Leigh P, Banati R: Evidence of widespread cerebral microglial activation in amyotrophic lateral sclerosis: an [11C](R)-PK11195 positron emission tomography study. Neurobiol Dis 2004, 15:601-609.

18. Troost D, Claessen N, van den Oord J, Swaab D, de Jong J: Neuronophagia in the motor cortex in amyotrophic lateral sclerosis. Neuropathol Appl Neurobiol 1993, 19:390-397.

19. Kawamata T, Akiyama H, Yamada T, McGeer P: Immunologic reactions in amyotrophic lateral sclerosis brain and spinal cord tissue. Am J Pathol 1992, 140:691-707.

20. Sekizawa T, Openshaw H, Ohbo K, Sugamura K, Itoyama Y, Niland J: Cerebrospinal fluid interleukin 6 in amyotrophic lateral sclerosis: immunological parameter and comparison with inflammatory and noninflammatory central nervous system diseases. J Neurol Sci 1998, 154:194-199.

21. Elliott J: Cytokine upregulation in a murine model of familial amyotrophic lateral sclerosis. Brain Res Mol Brain Res 2001, 95:172-178.

22. Hemmer K, Fransen L, Vanderstichele H, Vanmechelen E, Heuschling P: An in vitro model for the study of microglia-induced neurodegeneration: involvement of nitric oxide and tumor necrosis factor-alpha. Neurochem Int 2001, 38:557-565.

23. Hensley K, Fedynyshyn J, Ferrell S, Floyd R, Gordon B, Grammas P, Hamdheydari L, Mhatre M, Mou S, Pye Q, et al: Message and protein-level elevation of tumor necrosis factor alpha (TNF alpha) and TNF alphamodulating cytokines in spinal cords of the G93A-SOD1 mouse model for amyotrophic lateral sclerosis. Neurobiol Dis 2003, 14:74-80.

24. Weydt P, Yuen E, Ransom B, Möller T: Increased cytotoxic potential of microglia from ALS-transgenic mice. Glia 2004, 48:179-182.

25. Yoshihara T, Ishigaki S, Yamamoto M, Liang Y, Niwa J, Takeuchi H, Doyu M, Sobue G: Differential expression of inflammation- and apoptosis-related genes in spinal cords of a mutant SOD1 transgenic mouse model of familial amyotrophic lateral sclerosis. J Neurochem 2002, 80:158-167.

26. Sargsyan S, Blackburn D, Barber S, Monk P, Shaw P: Mutant SOD1 G93A microglia have an inflammatory phenotype and elevated production of MCP-1. Neuroreport 2009, 20:1450-1455.

27. Almer G, Guégan C, Teismann P, Naini A, Rosoklija G, Hays A, Chen C, Przedborski S: Increased expression of the pro-inflammatory enzyme cyclooxygenase-2 in amyotrophic lateral sclerosis. Ann Neurol 2001, 49:176-185.

28. Drew P, Xu J, Storer P, Chavis J, Racke M: Peroxisome proliferatoractivated receptor agonist regulation of glial activation: relevance to CNS inflammatory disorders. Neurochem Int 2006, 49:183-189.

29. Kriz J, Nguyen M, Julien J: Minocycline slows disease progression in a mouse model of amyotrophic lateral sclerosis. Neurobiol Dis 2002, 10:268-278.

30. Van Den Bosch L, Tilkin P, Lemmens G, Robberecht W: Minocycline delays disease onset and mortality in a transgenic model of ALS. Neuroreport 2002, 13:1067-1070.

31. Zhu S, Stavrovskaya I, Drozda M, Kim B, Ona V, Li M, Sarang S, Liu A Hartley D, Wu D, et al: Minocycline inhibits cytochrome c release and delays progression of amyotrophic lateral sclerosis in mice. Nature 2002, 417:74-78.
32. Gurney M, Cutting F, Zhai $P$, Andrus $P$, Hall E: Pathogenic mechanisms in familial amyotrophic lateral sclerosis due to mutation of $\mathrm{Cu}, \mathrm{Zn}$ superoxide dismutase. Pathol Biol (Paris) 1996, 44:51-56.

33. Ceballos-Picot I, Nicole A, Briand P, Grimber G, Delacourte A, Defossez A, Javoy-Agid F, Lafon M, Blouin J, Sinet P: Neuronal-specific expression of human copper-zinc superoxide dismutase gene in transgenic mice: animal model of gene dosage effects in Down's syndrome. Brain Res 1991, 552:198-214.

34. Epstein C, Avraham K, Lovett M, Smith S, Elroy-Stein O, Rotman G, Bry C, Groner Y: Transgenic mice with increased Cu/Zn-superoxide dismutase activity: animal model of dosage effects in Down syndrome. Proc Natl Acad Sci USA 1987, 84:8044-8048.

35. Avraham K, Schickler M, Sapoznikov D, Yarom R, Groner Y: Down's syndrome: abnormal neuromuscular junction in tongue of transgenic mice with elevated levels of human $\mathrm{Cu} / \mathrm{Zn}$-superoxide dismutase. Cell 1988, 54:823-829.

36. Yarom R, Sapoznikov D, Havivi Y, Avraham K, Schickler M, Groner Y: Premature aging changes in neuromuscular junctions of transgenic mice with an extra human CuZnSOD gene: a model for tongue pathology in Down's syndrome. J Neurol Sci 1988, 88:41-53.

37. Shibata N, Asayama K, Hirano A, Kobayashi M: Immunohistochemical study on superoxide dismutases in spinal cords from autopsied patients with amyotrophic lateral sclerosis. Dev Neurosci 1996, 18:492-498.

38. Deng H, Shi Y, Furukawa Y, Zhai H, Fu R, Liu E, Gorrie G, Khan M, Hung W, Bigio $E$, et al: Conversion to the amyotrophic lateral sclerosis phenotype is associated with intermolecular linked insoluble aggregates of SOD1 in mitochondria. Proc Natl Acad Sci USA 2006, 103:7142-7147.

39. Ezzi S, Urushitani M, Julien J: Wild-type superoxide dismutase acquires binding and toxic properties of ALS-linked mutant forms through oxidation. J Neurochem 2007, 102:170-178.

40. Hanisch $U$, Kettenmann $\mathrm{H}$ : Microglia: active sensor and versatile effector cells in the normal and pathologic brain. Nat Neurosci 2007, 10:1387-1394.

41. Nimmerjahn A, Kirchhoff F, Helmchen F: Resting microglial cells are highly dynamic surveillants of brain parenchyma in vivo. Science 2005, 308:1314-1318.

42. Davalos D, Grutzendler J, Yang G, Kim J, Zuo Y, Jung S, Littman D, Dustin M, Gan W: ATP mediates rapid microglial response to local brain injury in vivo. Nat Neurosci 2005, 8:752-758.

43. Raivich G, Haas S, Werner A, Klein M, Kloss C, Kreutzberg G: Regulation of MCSF receptors on microglia in the normal and injured mouse central nervous system: a quantitative immunofluorescence study using confocal laser microscopy. J Comp Neurol 1998, 395:342-358.

44. van Rossum D, Hanisch U: Microglia. Metab Brain Dis 2004, 19:393-411.

45. Capani F, Ellisman M, Martone M: Filamentous actin is concentrated in specific subpopulations of neuronal and glial structures in rat central nervous system. Brain Res 2001, 923:1-11.

46. Nolte C, Möller T, Walter T, Kettenmann H: Complement 5a controls motility of murine microglial cells in vitro via activation of an inhibitory G-protein and the rearrangement of the actin cytoskeleton. Neuroscience 1996, 73:1091-1107.

47. Dibaj P, Steffens H, Zschuntzsch J, Nadrigny F, Schomburg ED, Kirchhoff F, Neusch C: In Vivo Imaging Reveals Distinct Inflammatory Activity of CNS Microglia versus PNS Macrophages in a Mouse Model for ALS. PLOS One 2011, 6:e17910.

48. Brakebusch C, Fässler R: beta 1 integrin function in vivo: adhesion, migration and more. Cancer Metastasis Rev 2005, 24:403-411.

49. Breau M, Pietri T, Eder O, Blanche M, Brakebusch C, Fässler R, Thiery J, Dufour S: Lack of beta1 integrins in enteric neural crest cells leads to a Hirschsprung-like phenotype. Development 2006, 133:1725-1734.

50. Leone D, Relvas J, Campos L, Hemmi S, Brakebusch C, Fässler R, FfrenchConstant C, Suter U: Regulation of neural progenitor proliferation and survival by beta1 integrins. J Cell Sci 2005, 118:2589-2599.

51. Streit W, Kreutzberg G: Response of endogenous glial cells to motor neuron degeneration induced by toxic ricin. J Comp Neurol 1988, 268:248-263.

52. Pearson $H$, Payne $B$, Cunningham T: Microglial invasion and activation in response to naturally occurring neuronal degeneration in the ganglion cell layer of the postnatal cat retina. Brain Res Dev Brain Res 1993, 76:249-255. 
53. Thanos S: The Relationship of Microglial Cells to Dying Neurons During Natural Neuronal Cell Death and Axotomy-induced Degeneration of the Rat Retina. Eur J Neurosci 1991, 3:1189-1207.

54. Hetz C, Thielen P, Matus S, Nassif M, Court F, Kiffin R, Martinez G, Cuervo A, Brown $R$, Glimcher L: XBP-1 deficiency in the nervous system protects against amyotrophic lateral sclerosis by increasing autophagy. Genes Dev 2009, 23:2294-2306.

55. Hsieh C, Koike M, Spusta S, Niemi E, Yenari M, Nakamura M, Seaman W: A role for TREM2 ligands in the phagocytosis of apoptotic neuronal cells by microglia. J Neurochem 2009, 109:1144-1156.

56. Takahashi K, Prinz M, Stagi M, Chechneva O, Neumann H: TREM2transduced myeloid precursors mediate nervous tissue debris clearance and facilitate recovery in an animal model of multiple sclerosis. PLOS Med 2007, 4:e124.

57. Ralevic V, Burnstock G: Receptors for purines and pyrimidines. Pharmacol Rev 1998, 50:413-492.

58. Ohsawa K, Irino Y, Nakamura Y, Akazawa C, Inoue K, Kohsaka S: Involvement of P2X4 and P2Y12 receptors in ATP-induced microglial chemotaxis. Glia 2007, 55:604-616.

59. Inoue $\mathrm{K}$ : The function of microglia through purinergic receptors: neuropathic pain and cytokine release. Pharmacol Ther 2006, 109:210-226.

60. Tsuda M, Tozaki-Saitoh H, Inoue K: Pain and purinergic signaling. Brain Res Rev 2010, 63:222-232.

61. Lambert C, Ase AR, Seguela P, Antel JP: Distinct migratory and cytokine responses of human microglia and macrophages to ATP. Brain Behav Immun 2010, 24:1241-1248.

62. Inoue K: Purinergic systems in microglia. Cell Mol Life Sci 2008, 65:3074-3080.

63. McLarnon J: Purinergic mediated changes in $\mathrm{Ca} 2+$ mobilization and functional responses in microglia: effects of low levels of ATP. J Neurosci Res 2005, 81:349-356

64. D'Ambrosi N, Finocchi P, Apolloni S, Cozzolino M, Ferri A, Padovano V, Pietrini $G$, Carrì M, Volonté C: The proinflammatory action of microglial P2 receptors is enhanced in SOD1 models for amyotrophic lateral sclerosis. $\mathrm{J}$ Immunol 2009, 183:4648-4656.

65. Saura J, Tusell J, Serratosa J: High-yield isolation of murine microglia by mild trypsinization. Glia 2003, 44:183-189.

66. Cashman N, Durham H, Blusztajn J, Oda K, Tabira T, Shaw I, Dahrouge $S_{\text {, }}$ Antel J: Neuroblastoma $\times$ spinal cord (NSC) hybrid cell lines resemble developing motor neurons. Dev Dyn 1992, 194:209-221.

67. Menzies F, Cookson M, Taylor R, Turnbull D, Chrzanowska-Lightowlers Z, Dong L, Figlewicz D, Shaw P: Mitochondrial dysfunction in a cell culture model of familial amyotrophic lateral sclerosis. Brain 2002, 125:1522-1533.

68. Grosskreutz J, Haastert K, Dewil M, Van Damme P, Callewaert G, Robberecht W, Dengler R, Van Den Bosch L: Role of mitochondria in kainate-induced fast $\mathrm{Ca} 2+$ transients in cultured spinal motor neurons. Cell Calcium 2007, 42:59-69.

69. Haastert K, Grosskreutz J, Jaeckel M, Laderer C, Bufler J, Grothe C, Claus P: Rat embryonic motoneurons in long-term co-culture with Schwann cells-a system to investigate motoneuron diseases on a cellular level in vitro. J Neurosci Methods 2005, 142:275-284.

70. Grynkiewicz G, Poenie M, Tsien R: A new generation of Ca2+ indicators with greatly improved fluorescence properties. J Biol Chem 1985, 260:3440-3450.

doi:10.1186/1471-2202-12-91

Cite this article as: Sargsyan et al: A comparison of in vitro properties of resting SOD1 transgenic microglia reveals evidence of reduced neuroprotective function. BMC Neuroscience 2011 12:91.

\section{Submit your next manuscript to BioMed Central and take full advantage of:}

- Convenient online submission

- Thorough peer review

- No space constraints or color figure charges

- Immediate publication on acceptance

- Inclusion in PubMed, CAS, Scopus and Google Scholar

- Research which is freely available for redistribution

Submit your manuscript at www.biomedcentral.com/submit
Biomed Central 